\title{
Processes for the production of Oxymethylene ethers: Promising synthetic diesel additives
}

\author{
Authors: Tejas Bhatelia ${ }^{1,2}$, Woo Jin Lee ${ }^{1}$, Chanchal Samanta ${ }^{3}$ Jim Patel $^{1}$ and Ankur Bordoloi ${ }^{4}$ \\ ${ }^{1}$ CSIRO, 71 Normanby Road, Clayton North, Victoria 3169, Australia. \\ ${ }^{2}$ Department of Chemical and Biomolecular Engineering, The University of Melbourne, Parkville \\ Victoria 3010, Australia \\ ${ }^{3}$ Bharat Petroleum Corporation Itd., Corporate R\&D Centre, Plot No. 2A, Udyog Kendra, Greater \\ Noida, Uttar Pradesh-201306 \\ ${ }^{4}$ Nano catalysis, RTD, Indian Institute of Petroleum, Dehradun, UK-248005, INDIA \\ Corresponding Author: Ankur Bordoloi \\ Corresponding author email: ankurb@iip.res.in
}

This is the author manuscript accepted for publication and has undergone full peer review but has not been through the copyediting, typesetting, pagination and proofreading process, which may lead to differences between this version and the Version of Record. Please cite this article as doi: 10.1002/apj.2119

This article is protected by copyright. All rights reserved. 


\section{Introduction}

Stringent environmental regulations to address public health and reduce pollution are principal drivers for fuel quality improvements globally. Human activities (anthropogenic as well as emissions from motor vehicles) are main causes for growing environmental pollution leading to climate change and global temperature is rising at an alarming pace. To mitigate this threat, the Paris Agreement has entered into legal force on 4 November 2016. On 5 October 2016, the threshold for entry into force of the Paris Agreement was achieved as 115 Parties out of 197 Parties have ratified to the Convention. The Paris Agreement's central aim is to strengthen the global response to the threat of climate change by keeping a global temperature rise this century well below 2 degree Celsius above pre-industrial levels. It is also agreed to collectively pursue efforts to limit the temperature increase even further to 1.5 degree Celsius.

In order to fulfil this ambitious target, there is urgent need to improve overall carbon management in every aspect of our activities. Efficient combustion of fuels is an important aspect of carbon management. Complete combustion of fuel has several benefits

- Reduction in fuel consumption and more power and mileage from every litre fuel

- Lower emissions of $\mathrm{CO}$, particulate matter (PM), hydrocarbon or non-methane organic gases (NMOG)

- Reduction in NOx, and acid rain

- Reduction in equipment failure

- Reduction in maintenance costs

The dangers associated with environmentally damaging and toxic emissions, such as carbon, sulphur and nitrous oxides and particulates, are becoming increasingly apparent. Around the globe societies are responding to these dangers by imposing restrictions on the sectors responsible for these emissions. The combustion of transportation fuels is a significant source and consequently the automotive industry is an important sector grappling with this challenge.

Diesel is a critical fuel for many parts of modern economies due to its key role for the production of food and distribution of goods. The combustion of diesel in compression ignition engines is both attractive from a carbon dioxide emission perspective, but problematic in terms of nitrous oxides and particulates. Consequently diesel is an important but challenging fuel in this puzzle.

Thus, to combat air pollution, more efficient technologies are needed for both motor vehicles and fuels. The engine technology has evolved through the years and current engine technologies are much more efficient than their previous counterparts. On the other hand, significant thrusts have been given in developing cleaner fuels. Hydrogen, Bio-fuels viz. bioethanol, biodiesel, bio-methane, bio-DME, synthetic fuels such as gas to liquid (GTL) or biomass to liquid (BTL) gasoline, diesel etc. are emerging as efficient fuels of 21st century to overcome the environmental challenges associated 
with the fossil fuel combustion. However, these fuels contribute only a small share in current transportation fuel basket and will continue to do so in the near future.

Diesel fuel produced from crude oil is complex in nature and has many components. In this context, to meet the desired fuel specification and emission standards of diesel, various additives are being used and few more additives will be needed to improve the quality of diesel and to emission standards. Due to non-availability of direct $\mathrm{C}-\mathrm{C}$ on $\mathrm{OME}$ structure reduces the soot formation during combustion. The chemical structure $-\mathrm{O}-\mathrm{CH} 2$ - is responsible for the formation of hydroperoxides in combustion process in preliminary steps and further fragmented to hydroxide radicals, and then these radicals helps to oxidise the soot. Furthermore blending OME may lead to reduction of NOx too. One disadvantage of DME/diesel blends is requires the engine modification in fuel injection and fuel tank due to low viscosity and high vapour pressure of DME. Which is assumed to be overcome with OME because, it exhibits similar boiling points and viscosities to diesel. Moreover, OME have added advantage se like safe, more oxygen in structure for better combustion, superior ease of storage and transportations.

Many promising oxygenates reported in the literature have encountered end-use problems e.g. poor miscibility with diesel fuel or safety concerns. In addition, the economic feasibility of oxygenates may be challenging. In order to become an effective diesel fuel component, an oxygenated compound must satisfy the following five basic requirements:

- Ignition quality: cetane number min 51

- Flash point : above $55^{\circ} \mathrm{C}$

- Boiling point: close to range of $118-340^{\circ} \mathrm{C}$

- Solubility in diesel fuel : soluble in diesel fuel

- Production : Should be produced from low-cost widely available feedstock and with simple process steps

Oxymethylene ethers (OME) or Poly (oxymethylene) dimethyl ethers (POMDMEs), having the chemical structure of $\mathrm{CH}_{3}-\mathrm{O}-\left(\mathrm{CH}_{2}-\mathrm{O}-\right) \mathrm{n}-\mathrm{CH}_{3}$, are attractive components for tailoring diesel fuel (OMEs, Figure 1). Some of the important fuel characteristics mentioned below need to be considered when oxygenated substances to be evaluated as diesel additives:

- Miscibility with diesel fuel - oxygenates are generally polar in nature, which may lead to compatibility problems when blended with diesel;

- Energy density - the energy content of oxygenates is lower than that of hydrocarbon fuels resulting in modifications to fuel injection systems, larger fuel tanks or reduced range;

- Viscosity - low viscosity of fuels may cause leakages, while high viscosity may over-load the injection system;

- Lubricity - some oxygenates require the addition of lubricity agents;

- Cetane number - high cetane numbers generally lead to decreased ignition delays and higher combustion temperatures, consequently increasing particulate matter emission and products of incomplete combustion, whereas NOx emission may increase; 
- Particulate matter emissions - such emissions can be reduced when fuel contains oxygen, but this is not a linear phenomenon and the nature of functional groups may overrule the effect of the oxygen content;

- Engine load and emission control characteristics are also important parameters

In short, the optimum diesel oxygenate would be compatible with unmodified compression-ignition engines and infrastructure. Some fundamental factors that promotes favourable oxygenate chemistry include:

- Short carbon chains;

- Linear carbon chains are better than their non-linear counterparts;

- Symmetrical position of oxygen in ethers;

- Cetane number, density, viscosity, boiling point etc. are also important factors.

Similar to the simplest of the ethers, dimethyl ether (DME), OMEs have interesting combustion characteristics. Synthesised from hydrocarbons via syngas, OMEs contain very little sulphur, and with a relatively high proportion of oxygen in their composition, they burn with little soot formation. Also similar to DME, OMEs have high cetane numbers ranging from ca. 70 to 100, which make them excellent candidates for use in compression ignition engines. However, unlike DME, the physical properties of particular OMEs make them suitable replacement to diesel fuels.

Given that each of the key intermediates for the production of OMEs, methanol, formaldehyde, trioxane and $\mathrm{DME}$, is typically produced from syngas, the feedstocks for the production of $\mathrm{OME}$ include natural gas, coal and biomass. The smallest of the $\mathrm{OMEs}, \mathrm{OME}_{1}$ (also known as Dimethoxy methane/DMM), is a key intermediate in several of the processes developed for the production of higher OMEs and although it has its own interesting applications, it is not suitable for $\mathrm{Cl}$ engines. Higher OMEs have physical properties close to those of diesel and hence are potentially "drop-in fuels" for diesel engines. Table 1 provides the details of the physical properties of different OMEs compared with diesel fuel (CDF) and other oxygenated fuel options:

As it can be seen from Table 1, OMEs with $n=3-5$ have viscosities and boiling points which are more attractive for transport fuel applications compared to $\mathrm{DME}$ and $\mathrm{OME}_{1}$. It is also known that OMEs with $n=3-5$ are soluble in diesel. The purpose of this commentary is to briefly describe the studies reported on the use of OMEs in $\mathrm{Cl}$ engines and to provide as detailed summary of the known synthetic routes to OMEs and their pros and cons.

\section{Status of research in the area}

OME is gaining importance both in academic and industrial R\&D as evidenced by the patents and publication trends and involvement various research organizations in the development of OME process technology. The number of publications and patents on OMEs have increased steadily in the last ten years, revealing a renewed interest in OMEs. This is mainly because of the stringent 
environmental regulations worldwide to reduce exhaust emissions. China's proactive energy policy combined with the scale of its economy and infrastructure development is promoting regional as well as global clean energy related research. As evidence, China's oil companies and research institutes are very active in this area as evident by the fact that more than $70 \%$ of research outputs are coming from China. BASF and BP are also active in the research and development on OMEs.

Very recently, the German Federal Ministry of Food and Agriculture (BMEL) via FNR (Fachagentur Nachwachsende Rohstoffe e.V.), BMEL's central project-coordinating agency in the area of renewable resources, has funded (with $€ 800,000$ ) a 3-year project to study of oxymethylene ethers (OME) as clean diesel fuels Karlsruhe Institute of Technology (KIT) is the coordinator of the new project, in cooperation with TU Kaiserslautern and TU München.

\section{OME as a fuel}

An early description of the use of OMEs in Cl engines was described in early 90's by Naegili and coworkers ${ }^{[1]}$. However, recently there have been a resurgence in the number of papers and reports which describe the use of $\mathrm{OME}_{3-8}$ as both blend and pure (/neat) fuel in compression ignition engines. Lumpp et al. ${ }^{[2]}$ reported a substantial reduction in PM, soot and the particle number with a $20 \% \mathrm{v} / \mathrm{v}$ blend of OME $(n=3,4)$ in B7 diesel fuel over the ESC/ETC cycles in a Euro V heavy-duty sixcylinder engine. They also reported a decrease in soot emissions with a $10 \%$ blend of OMEs in $\mathrm{BO}$ diesel fuel about to $40 \%$ depending on the operation.

The majority of the recent studies have been reported by a group of Italian researchers from Istituto Motori CNR ${ }^{[3-5]}$. This group has conducted a series of studies to elucidate the emissions characteristics of OMEs (blend and neat) in various $\mathrm{Cl}$ engine applications. Some of their findings include:

1) When neat OME was used the $C O$ and formaldehyde emissions were high. They have attributed this to the High concentration of $\mathrm{C}-\mathrm{O}$ bonds.

2) Neat OMEs burned at higher temperature, which resulted in the elevated levels of NOx emissions

3) High emission of formaldehyde and the finer particle size of the emitted PM are intrinsically related to the unique chemical structure of OMEs that does not have any $\mathrm{C}-\mathrm{C}$ bond.

4) It is also necessary to compensate or alleviate the degradation of engine performance, e.g. maximum power and torque at high speed, due to the lower volumetric LVH. This would require the development of new ad hoc fuel injection systems and after treatment devices.

a. fuel injection system with higher volumetric flow rate

b. DOC should have a stronger oxidative activity, in particular towards formaldehyde

More recently they conducted a detail study in a Euro-3 engine, fuelled with a blended (up to 7.5\%) OMEs, on the emissions of polyaromatic hydrocarbons (PAH) and particle number size distribution $(P N S D)^{[5]}$. It was observed that the number of particles less than $30 \mathrm{~nm}$ increased at low load and speed, whereas at higher speeds and load the larger particle $(>30 \mathrm{~nm})$ were reduced. They also found 
that the PAH emissions were higher for OMEs blended fuel. They attributed these results to lowered catalytic activity due to observed elevated exhaust gas temperatures. This remains the subject of interest and more work is needed to understand these trade-offs.

In summary, there is very little work reported to advance our understanding of the behaviour of neat OMEs as a fuel. The handful of papers that have been reported suggest the following:

1) Compared to conventional diesel OME combustion significantly reduces particulate emissions but there is an increase number of ultra-fine PM

2) Reduced $\mathrm{CO}$ and slightly increased $\mathrm{NO}_{x}$

3) For $\mathrm{Cl}$ engines $\mathrm{OME}_{1}$ blends are not entirely desirable as they will require modifications fuel injection system; however there may be some modification required in OMEs too.

\section{OME Production Processes}

\section{Synthesis of (OME)}

There are several possible pathways for the production of OMEs. The most commonly cited pathway involves the reaction of $\mathrm{OME}_{1}$ with Formaldehyde ${ }^{[6]}$. Several research papers from 1960s describe this process, however the purpose was primarily for production of OMEs with $n>50$. There has been a resurgence in developing further understanding of the process to produce OMEs with $n=3-8$. We review some of the processes that are proposed in literature for producing the OMEs $(n=3-8)$ and $\mathrm{OME}_{1}$.

OMEs synthesis reactions are acid-catalysed reaction between methanol and trioxane (or formaldehyde). However, as the processes often produce formaldehyde from methanol and DME, it usually contains several different catalysts-redox metal catalysts and acidic catalysts. BP introduced the catalytic process using the mixture of $\mathrm{DME} / \mathrm{MeOH}$, where formaldehyde is produced via the oxidative dehydrogenation (R1) and then the produced formaldehyde is further reacted with DME and $\mathrm{MeOH}$ to produce $\mathrm{OME}_{1}$ and $\mathrm{OMEn}(\mathrm{R} 2 \& \mathrm{R} 3)$.

$\mathrm{CH}_{3} \mathrm{OCH}_{3}+1 / 2 \mathrm{O}_{2} \rightarrow 2 \mathrm{CH}_{2} \mathrm{O}+\mathrm{H}_{2}$ (Ag catalyst)

$\mathrm{CH}_{3} \mathrm{OCH}_{3}+\mathrm{CH}_{2} \mathrm{O} \rightarrow \mathrm{CH}_{3} \mathrm{O}-\left(\mathrm{CH}_{2} \mathrm{O}\right)-\mathrm{CH}_{3}$ (Borosilicate MFI catalyst)

$2 \mathrm{CH}_{3} \mathrm{OH}+\mathrm{nCH}_{2} \mathrm{O} \rightarrow \mathrm{CH}_{3} \mathrm{O}-\left(\mathrm{CH}_{2} \mathrm{O}\right)_{n}-\mathrm{CH}_{3}+\mathrm{H}_{2} \mathrm{O}$ (cation exchange resin)

BASF invented the process using the mixture of $\mathrm{OME}_{1}$ and trioxane in the presence of acid catalysts, in which the continuous stirred tank reactor and fixed-bed reactors are employed.

$$
\rightarrow 3 \mathrm{CH}_{2} \mathrm{O} \text { (liquid sulphuric acid) }
$$


As shown in Table 2, some major drawbacks from these processes still need to be addressed. The low yield and complicated process are main drawbacks for BP process whereas the corrosive catalyst and low selectivity are observed from BASF process. Although the high yield (> 50\%) are achievable from Lanzhou method, the ionic liquid are expensive and also separation of the product from the homogeneous effluent can load more effort in the downstream.

In summary, all the processes for producing OME use either methanol or DME as a feed stock. Industrially, the production of OMEs has been operated in two main processes, in which the BP processes ${ }^{[7]}$ use mainly solid acid catalysts and BASF processes ${ }^{[8-10]}$ employ the liquid acidic catalysts. We have reviewed main challenges and opportunities in these processes and provided here some important aspects that may help in guiding future research directions.

\section{One-step synthesis route of $O \mathrm{ME}_{1}$}

There have been considerable efforts on the direct synthesis of $\mathrm{OME}_{1}$ (or methylal) through the selective oxidation of methanol. Typically, this pathway includes two steps in terms of the function of catalysts, where methanol is firstly oxidised to formaldehyde on redox sites and the produced formaldehyde reacts with another methanol to form $\mathrm{OME}_{1}$ on acidic sites ${ }^{[11]}$. Key factor for high yield of $\mathrm{OME}_{1}$ is the maintenance of appropriate balance between redox ability and acidity of the catalysts $^{[6]}$. When redox cites are excessive against acidic sites, it leads to the production of methyl formate. The inverse would produce more dimethyl ether as a main product.

Figure 2 shows the typical mechanism of the $\mathrm{OME}_{1}$ production through the redox-acidic cycles including the methanol oxidation and acetalization of formaldehyde and methanol on acidic function ${ }^{[11]}$. In this route, methanol oxidation is activated by the electrons transferred from lattice oxygen and metal cation during the redox process, followed by the acetalization by means of the enrichment of weak $\mathrm{Br} \varnothing$ nsted acidic sites on the $\mathrm{\gamma}-\mathrm{Al}_{2} \mathrm{O}_{3}$ surface. As deduced, the combined effects from the redox cycle of $\mathrm{V}$-Mo oxides and acidic role of $\mathrm{Y}-\mathrm{Al}_{2} \mathrm{O}_{3}$ surface should be attributed to the high yield of $\mathrm{OME}_{1}$. It is generally considered that the important factors determining catalytic activity are redox property in metal oxides, electron and lattice oxygen mobility and surface acidic properties. Redox property of metal oxides would be closely related to the metal-oxygen bond strength ${ }^{[12]}$. When the supported metal oxides are considered, the support material would also influence critically the catalytic activity. For instance, in the case of vanadium oxide catalysts, particularly those with monolayer coverage, it was found that the turnover frequency (TOF) for methanol oxidation decreased in the following order: $\mathrm{V}_{2} \mathrm{O}_{5} \mathrm{~V}_{2} \mathrm{O} 5 / \mathrm{CeO}_{2}\left(1.0 \times 10^{0} \mathrm{~s}^{-1}\right), \mathrm{V}_{2} \mathrm{O}_{5} / \mathrm{ZrO}_{2}$ $\left(1.7 \times 10^{-1} \mathrm{~s}^{-1}\right), \mathrm{V}_{2} \mathrm{O}_{5} / \mathrm{TiO}_{2}\left(1.1 \times 10^{01} \mathrm{~s}^{-1}\right), \mathrm{V}_{2} \mathrm{O}_{5} / \mathrm{Nb}_{2} \mathrm{O}_{5}\left(4.0 \times 10^{-2} \mathrm{~s}^{-1}\right), \mathrm{V}_{2} \mathrm{O}_{5} / \mathrm{Al}_{2} \mathrm{O}_{3}\left(6.8 \times 10^{-3} \mathrm{~s}^{-1}\right)$ and $\mathrm{V}_{2} \mathrm{O}_{5} / \mathrm{SiO}_{2}\left(2.3 \times 10^{-4} \mathrm{~s}^{-1}\right)^{[13]}$. Therefore, the correlation between all these aspects to the optimized activity should be greatly taken into account in designing the catalysts.

Table 3 summarizes the reaction conditions and the yield of $\mathrm{OME}_{1}$ when the various catalysts were used for the selective oxidation of methanol. Depending on the catalysts employed, the reaction temperature can be as low as $120^{\circ} \mathrm{C}$. The one-step production of $\mathrm{OME}_{1}$ from methanol will give more 
feasible pathways to reach $\mathrm{OME}_{3-8}$. Indeed, the conversion of methanol to formaldehyde is often operated in high temperature with the catalysts of low activity. This will clearly render the currently known technologies difficult to be optimized. Based on the literature review in this topic, there are quite a few good catalysts to indicate good level of yield for $\mathrm{OME}_{1}$ (See Table 2). The range of catalysts, which are mainly solid phase, include heteropoly acid catalysts such as Keggin cluster ${ }^{[14-15]}$, V-based catalyst ${ }^{[11,16-17]}, \mathrm{V}^{-\mathrm{TiO}_{2}}$ based catalysts ${ }^{[16,18-25]}$, Re-based catalysts ${ }^{[26-28]}$, and Fe-Mo based catalysts ${ }^{[29-32]}$. Once $\mathrm{OME}_{1}$ is produced in a sufficient level, one can directly combine this with the process that can deliver formaldehyde groups (i.e. condensation reaction), which will often be operated in the temperature lower than $100^{\circ} \mathrm{C}$. Therefore, in this case, the overall energy consumption for the process would decrease significantly.

We compared the performance of different catalysts for the selective methanol oxidation Figure 3 presents the level of conversion of methanol as a function of reaction temperature using vanadiumcontaining catalysts and other active metal containing catalysts. It shows clearly that V-containing catalysts showed much higher conversion and yield of $\mathrm{OME}_{1}$ at the lower temperature. Yield of $\mathrm{OME}_{1}$ could reach around $60 \%$ at the temperature lower than $150^{\circ} \mathrm{C}$ when the amorphous $\mathrm{Mo}_{12} \mathrm{~V}_{3} \mathrm{~W}_{1.2} \mathrm{Cu}_{1.2} \mathrm{Sb}_{0.5} \mathrm{O}_{\mathrm{x}}$ was used as a catalyst ${ }^{[33]}$. Methanol oxidation would lead to the high yield of $\mathrm{OME}_{1}$ as long as $\mathrm{V}_{2} \mathrm{O}_{5}$ is incorporated with other components in which its superior redox property is maintained. Interestingly, the different form of vanadium oxide seems to be still promising for the same reaction. When the $\mathrm{V}_{2} \mathrm{O}_{5}$ is presented in the form of nanofiber, the high yield of $\mathrm{OME}_{1}$ is still obtained $^{[22]}$. Though mesoporous aluminosilicate supports were also tested ${ }^{[15,31]}$, the levels of yield for $\mathrm{OME}_{1}$ were not comparable -9 and $0.5 \%$ for SBA-15 and MCM-41, respectively. While most studies for the direct synthesis of $\mathrm{OME}_{1}$ were carried by means of the commonly available supports such as $\mathrm{TiO}_{2}, \mathrm{~N}$-doped mesoporous carbon was tested as a support ${ }^{[12]}$. However, the conclusion was not convinced due to the lack of comparable studies using carbon supports.

From the patents issued recently, it is found that the yield of $\mathrm{OME}_{1}$ could reach higher than $70 \%$ when V-based catalysts were employed. Table 4 shows the comparison between the one-step processes using the catalysts of different components. Compared to those employing Mo-Fe catalyst and multi-components catalyst, $\mathrm{Ce}-\mathrm{V}$ - $\mathrm{Ti}$ oxide supported $\mathrm{V}_{2} \mathrm{O}_{5}$ catalyst was reported to show the highest yield of $76 \%$ at the low temperature region ${ }^{[34]}$. To the best our knowledge, little process was reported on the combination of one-step production of $\mathrm{OME}_{1}$ and one that provides formaldehyde groups to achieve the high yield of $\mathrm{OME}_{3-8}$ in industrial scale.

\section{Formaldehyde routes}

\section{BP process}

This process mainly requires reaction of $\mathrm{OME}_{1}$ and formaldehyde. Formaldehyde can be produced by oxidation reaction of methanol over metal oxide catalysts $(\mathrm{Fe}, \mathrm{Mo}, \mathrm{V}, \mathrm{Ag})$. Thereafter, methanol and formaldehyde react to form $\mathrm{OME}_{1}$. There after formaldehyde reacts with $\mathrm{OME}_{1}$ (using the same catalyst) to form OMEs. The process produces water as the by-product which can react with 
formaldehyde to form methylene glycol and poly (oxymethylene) glycols and are the undesired products of the process. The process also requires a series of separations which are complex and hinder the techno-economic feasibility. This process is feasible but leads to a process with complicated separations.

The production by means of solid acid catalysts usually leads to the low yield whereas one with liquid acidic catalysts has the problem of corrosion in the equipments. Apart from these major issues, as shown in Table 2 below, both BP and BASF processes have still several critical limitations. More specifically, BP processes has the high complexity due to the multiple steps, which is inevitably leading to the high cost for capital and maintenance. In addition, the dimer $\left(\mathrm{OME}_{\mathrm{n}=2}\right)$, the main product consisting of $83 \%$ in overall product composition, has low-boiling point and can be hydrolysed to form hemiacetal and methanol. Surely, this feature will hamper the direct application to diesel engines.

\section{Lanzhou Process}

Recently, Lanzhou institute ${ }^{[35-36]}$ reported the process using the functional ionic liquid as a catalyst. They claimed that $\mathrm{OME}_{3-6}$ consisted of $90 \%$ in the overall composition of products and the dimer concentration was only around $4 \%$. However, ionic liquids are expensive materials and multiple rectification units are still required for separating the target products from methanol and extractants (such as hexane).

\section{Trioxane route (BASF Process)}

The process using Trioxane as an intermediate involves converting methanol to formaldehyde which is then converted to $\mathrm{OME}_{1}$ and Trioxane which reacts to form OMEs. However, it is speculated that the Trioxane dehydrogenates and form formaldehyde (in situ) which reacts with $\mathrm{OME}_{1}$ to form OMEs. Methanol to formaldehyde conversion is easy and well known in open literature. Trioxane is produced by the trimerization of formaldehyde which is usually catalysed by $\mathrm{H}_{2} \mathrm{SO}_{4}$ and $\mathrm{OME}_{1}$ is produced by heterogeneously catalysed reactive distillation process. These processes are also well understood in literature and operate on industrial scales ${ }^{[37-38]} . \mathrm{OME}_{1}$ and Trioxane reaction was studied in detail by Burger and co-workers. They have reported considerable work on this process and have proposed a process that involves a fixed-bed reactor filled with the Amberlyst 46 catalyst and two distillation columns to selectively produce $\mathrm{OMEs}_{n=3-5}{ }^{[39-42]}$. In BASF processes, the separation processes still requires high energy consumption due to the large amount of absorbents. Further, liquid-phase acidic catalysts would not be easily recycled and trioxymethylene is not a cheap reactant to replace formaldehyde. Good miscibility and formation of azeotrope, methanol, water and OME are difficult to be separated in actual operation.

\section{DME route}

In this process dimethyl ether is reacted with trioxane over an acidic catalyst to form OMEs. Acidic catalyst such as sulphuric acid or heterogeneous Amberlite ${ }^{\circledR}$ IR 120 ion exchange resin can be used for this process. The process is carried out using one reactor and 3 distillation columns, where 
different $\mathrm{n}$ of OMEs are separated in each of the columns. Recycling plays an important role in determining the final $\mathrm{n}$ of the product. This option is quite attractive however an appropriate catalytic system is required and is missing from open literature.

\section{Future directions and conclusion}

Although a lot of work has been carried out till date, the process is by far optimized and there is a lot of opportunities for research and development. In feedstock space, instead of using $\mathrm{OME}_{1}$ and Trioxane, systematic and through studies are required for developing processes based of more available feedstocks like methanol and formaldehyde. Designing of a catalytic system for the production of OMEs is a critical part for the overall performance of the processes. High level of conversion for the reactants and the acceptable yield level for the target products such as $\mathrm{OME}_{3-8}$ should be obtainable through such catalytic systems. This is surely because the highly selective process will mitigate the extent of equipment in the downstream. Intrinsic property of metal oxides, effect of supporting material and addition of appropriate additives are typical considerations when tailoring the catalysts. More importantly, the correlation between all these aspects should be carefully taken into account in terms of the final outcomes.

Some fundamental studies also required in reaction area to develop efficient catalyst system and process. Other aspects like energy efficient processes develop a reactor/catalyst system that can produce a fixed product range not a Schulz-Flory type distribution, separation of the products and combination of new reactants and find out the simpler pathways to develop process. The opportunity lies in technologies such as reactive/extractive distillations for intensifying this process. Engine efficiencies needs to normalised with OME and improvements have to be made in SCR technology to reduce the NOx up to nearly zero level. Which leads to a development of a new type of catalytic convertors.

\section{References}

[1] Naegeli, D., Fuel additives for smoke reduction in diesel engines. Southwest Research Institute Report, 1992, 03-130.

[2] Lumpp, B.; Rothe, D.; Pastötter, C.; Lämmermann, R.; Jacob, E., Oxymethylene ethers as diesel fuel additives of the future. MTZ Worldw 2011, 72 (3), 34-38.

[3] Pellegrini, L.; Marchionna, M.; Patrini, R.; Beatrice, C.; Del Giacomo, N.; Guido, C., Combustion Behaviour and Emission Performance of Neat and Blended Polyoxymethylene Dimethyl Ethers in a Light-Duty Diesel Engine. SAE International: 2012.

[4] Pellegrini, L.; Marchionna, M.; Patrini, R.; Florio, S., Emission Performance of Neat and Blended Polyoxymethylene Dimethyl Ethers in an Old Light-Duty Diesel Car. SAE International: 2013.

[5] Pellegrini, L.; Patrini, R.; Marchionna, M., Effect of POM-DME Blend on PAH Emissions and Particulate Size Distribution from an In-Use Light-Duty Diesel Engine. SAE International: 2014.

[6] Arvidson, M.; Fakley, M. E.; Spencer, M. S., Lithium halide-assisted formation of polyoxymethylene dimethyl ethers from dimethoxymethane and formaldehyde. Journal of Molecular Catalysis 1987, 41 (3), 391 393. 
[7] Hagen, G. P.; Spangler, M. J. Preparation of polyoxymethylene dimethyl ethers by catalytic conversion of dimethyl ether with formaldehyde formed by oxy-dehydrogenation of dimethyl ether. 1999.

[8] Stroefer, E.; Hasse, H.; Blagov, S. Process for preparing polyoxymethylene dimethyl ethers from methanol and formaldehyde. 2010.

[9] Stroefer, E.; Hasse, H.; Blagov, S. Method for Producing Polyoxymethylene Dimethyl Ethers From Methanol and Formaldehyde. 2008.

[10] Stroefer, E.; Schelling, H.; Hasse, H.; Blagov, S. in aqueous solution using acid catalyst; multistage distillation, separation. 2011.

[11] Meng, Y.; Wang, T.; Chen, S.; Zhao, Y.; Ma, X.; Gong, J., Selective oxidation of methanol to dimethoxymethane on $\mathrm{V}_{2} \mathrm{O}_{5}-\mathrm{MoO}_{3} / \mathrm{Y}-\mathrm{Al}_{2} \mathrm{O}_{3}$ catalysts. Applied Catalysis B: Environmental 2014, 160-161, 161172.

[12] Kim, H.; Park, D. R.; Park, S.; Jung, J. C.; Lee, S.-B.; Song, I. K., Preparation, characterization, and catalytic activity of $\mathrm{H}_{5} \mathrm{PMO}_{10} \mathrm{~V}_{2} \mathrm{O}_{40}$ immobilized on nitrogen-containing mesoporous carbon $\left(\mathrm{PMo}_{10} \mathrm{~V}_{2} / \mathrm{N}-\mathrm{MC}\right)$ for selective conversion of methanol to dimethoxymethane. Korean Journal of Chemical Engineering 2009, 26 (3), 660-665.

[13] Burcham, L. J.; Deo, G.; Gao, X.; Wachs, I. E., In situ IR, Raman, and UV-Vis DRS spectroscopy of supported vanadium oxide catalysts during methanol oxidation. Topics in Catalysis 2000, 11 (1-4), 85-100.

[14] Liu, H.; Iglesia, E., Effects of support on bifunctional methanol oxidation pathways catalyzed by polyoxometallate Keggin clusters. Journal of Catalysis 2004, 223 (1), 161-169.

[15] Guo, H.; Li, D.; Xiao, H.; Zhang, J.; Li, W.; Sun, Y., Methanol selective oxidation to dimethoxymethane on H3PMo12O40/SBA-15 supported catalysts. Korean Journal of Chemical Engineering 2009, 26 (3), $902-906$.

[16] Zhao, Y.; Qin, Z.; Wang, G.; Dong, M.; Huang, L.; Wu, Z.; Fan, W.; Wang, J., Catalytic performance of $\mathrm{V}_{2} \mathrm{O}_{5} / \mathrm{ZrO}_{2}-\mathrm{Al}_{2} \mathrm{O}_{3}$ for methanol oxidation. Fuel 2013, 104, 22-27.

[17] Chen, S.; Meng, Y. L.; Zhao, Y. J.; Ma, X. B.; Gong, J. L., Selective Oxidation of Methanol to Dimethoxymethane over Mesoporous Al-P-V-O Catalysts. AlChE Journal 2013, 59 (7), 2587-2593.

[18] Guo, H.; Li, D.; Jiang, D.; Li, W.; Sun, Y., Characterization and performance of sulfated $\mathrm{VOx}^{-\mathrm{TiO}_{2}}$ catalysts in the one-step oxidation of methanol to dimethoxymethane. Catalysis Communications 2010, 11 (5), 396-400.

[19] Sun, Q.; Fu, Y.; Liu, J.; Auroux, A.; Shen, J., Structural, acidic and redox properties of $\mathrm{V}_{2} \mathrm{O}_{5}-\mathrm{TiO}_{2}-\mathrm{SO}_{42}-$ catalysts. Applied Catalysis A: General 2008, 334 (1-2), 26-34.

[20] Fan, Z.; Guo, H.; Fang, K.; Sun, Y., Efficient $\mathrm{V}_{2} \mathrm{O}_{5} / \mathrm{TiO}_{2}$ composite catalysts for dimethoxymethane synthesis from methanol selective oxidation. RSC Advances 2015, 5 (31), 24795-24802.

[21] Zhao, H.; Bennici, S.; Cai, J.; Shen, J.; Auroux, A., Influence of the metal oxide support on the surface and catalytic properties of sulfated vanadia catalysts for selective oxidation of methanol. Journal of Catalysis 2010, 274 (2), 259-272.

[22] Liu, J.; Fu, Y.; Sun, Q.; Shen, J., $\mathrm{TiO}_{2}$ nanotubes supported $\mathrm{V}_{2} \mathrm{O}_{5}$ for the selective oxidation of methanol to dimethoxymethane. Microporous and Mesoporous Materials 2008, 116 (1-3), 614-621.

[23] Guo, H.; CongbiaoChen; Xiao, Y.; Wang, J.; Fan, Z.; Li, D.; Sun, Y., Influence of preparation method on the surface and catalytic properties of sulfated vanadia-titania catalysts for partial oxidation of methanol. Fuel Processing Technology 2013, 106, 77-83.

[24] Zhao, H.; Bennici, S.; Shen, J.; Auroux, A., Nature of surface sites of catalysts and reactivity in selective oxidation of methanol to dimethoxymethane. Journal of Catalysis 2010, 272 (1), 176-189.

[25] Kaichev, V. V.; Popova, G. Y.; Chesalov, Y. A.; Saraev, A. A.; Zemlyanov, D. Y.; Beloshapkin, S. A.; KnopGericke, A.; Schlögl, R.; Andrushkevich, T. V.; Bukhtiyarov, V. I., Selective oxidation of methanol to form dimethoxymethane and methyl formate over a monolayer $\mathrm{V}_{2} \mathrm{O}_{5} / \mathrm{TiO}_{2}$ catalyst. Journal of Catalysis 2014, 311, 59-70.

[26] Nikonova, O. A.; Capron, M.; Fang, G.; Faye, J.; Mamede, A.-S.; Jalowiecki-Duhamel, L.; Dumeignil, F.; Seisenbaeva, G. A., Novel approach to rhenium oxide catalysts for selective oxidation of methanol to DMM. Journal of Catalysis 2011, 279 (2), 310-318. 
[27] Yuan, Y.; Iwasawa, Y., Performance and Characterization of Supported Rhenium Oxide Catalysts for Selective Oxidation of Methanol to Methylal. The Journal of Physical Chemistry B 2002, 106 (17), 4441-4449.

[28] Sécordel, X.; Yoboué, A.; Cristol, S.; Lancelot, C.; Capron, M.; Paul, J.-F.; Berrier, E., Supported oxorhenate catalysts prepared by thermal spreading of metal Re0 for methanol conversion to methylal. Journal of Solid State Chemistry 2011, 184 (10), 2806-2811.

[29] Gornay, J.; Secordel, X.; Tesquet, G.; de Menorval, B.; Cristol, S.; Fongarland, P.; Capron, M.; Duhamel, L.; Payen, E.; Dubois, J.-L.; Dumeignil, F., Direct conversion of methanol into 1,1-dimethoxymethane: remarkably high productivity over an FeMo catalyst placed under unusual conditions. Green Chemistry 2010, $12(10), 1722-1725$.

[30] Faye, J.; Capron, M.; Takahashi, A.; Paul, S.; Katryniok, B.; Fujitani, T.; Dumeignil, F., Effect of oxomolybdate species dispersion on direct methanol oxidation to dimethoxymethane over $\mathrm{MoOx} / \mathrm{TiO}_{2}$ catalysts. Energy Science \& Engineering 2015, 3 (2), 115-125.

[31] Shannon, I. J.; Maschmeyer, T.; Oldroyd, R. D.; Sankar, G.; Thomas, J. M.; Pernot, H.; Balikdjian, J.-P.; Che, M., Metallocene-derived, isolated MoVI active centres on mesoporous silica for the catalytic dehydrogenation of methanol. Journal of the Chemical Society, Faraday Transactions 1998, 94 (10), 1495-1499.

[32] Thavornprasert, K.-a.; Capron, M.; Jalowiecki-Duhamel, L.; Gardoll, O.; Trentesaux, M.; Mamede, A.-S.; Fang, G.; Faye, J.; Touati, N.; Vezin, H., Highly productive iron molybdate mixed oxides and their relevant catalytic properties for direct synthesis of 1, 1-dimethoxymethane from methanol. Applied Catalysis B: Environmental 2014, 145, 126-135.

[33] Royer, S.; Secordel, X.; Brandhorst, M.; Dumeignil, F.; Cristol, S.; Dujardin, C.; Capron, M.; Payen, E.; Dubois, J.-L., Amorphous oxide as a novel efficient catalyst for direct selective oxidation of methanol to dimethoxymethane. Chemical Communications 2008, (7), 865-867.

[34] Fuyu Chuan, L. J., Shen Jianyi V2O5 composite catalyst loaded by Ce-V-Ti-O meso-material 2010.

[35] Xia, C.; Song, H.; Chen, J.; Jin, F.; Kang, M. System and method for continuously producing polyoxymethylene dimethyl ethers. 2012.

[36] Chen, J.; Song, H.; Xia, C.; Kang, M.; Jin, R. System and method for continuously producing polyoxymethylene dialkyl ethers. 2012.

[37] Grützner, T.; Hasse, H.; Lang, N.; Siegert, M.; Ströfer, E., Development of a new industrial process for trioxane production. Chemical Engineering Science 2007, 62 (18-20), 5613-5620.

[38] Masamoto, J.; Matsuzaki, K., Development of Methylal Synthesis by Reactive Distillation. Journal of Chemical Engineering of Japan 1994, 27 (1), 1-5.

[39] Burger, J.; Hasse, H., Multi-objective optimization using reduced models in conceptual design of a fuel additive production process. Chemical Engineering Science 2013, 99 (0), 118-126.

[40] Burger, J.; Siegert, M.; Ströfer, E.; Hasse, H., Poly(oxymethylene) dimethyl ethers as components of tailored diesel fuel: Properties, synthesis and purification concepts. Fuel 2010, 89 (11), 3315-3319.

[41] Burger, J.; Ströfer, E.; Hasse, H., Chemical Equilibrium and Reaction Kinetics of the Heterogeneously Catalyzed Formation of Poly(oxymethylene) Dimethyl Ethers from Methylal and Trioxane. Industrial \& Engineering Chemistry Research 2012, 51 (39), 12751-12761.

[42] Burger, J.; Ströfer, E.; Hasse, H., Production process for diesel fuel components poly(oxymethylene) dimethyl ethers from methane-based products by hierarchical optimization with varying model depth. Chemical Engineering Research and Design 2013, 91 (12), 2648-2662.

[43] Li, M.; Long, Y.; Deng, Z.; Zhang, H.; Yang, X.; Wang, G., Ruthenium trichloride as a new catalyst for selective production of dimethoxymethane from liquid methanol with molecular oxygen as sole oxidant. Catalysis Communications 2015, 68, 46-48.

[44] Yu, P.; Liu, J.; Rong, J.; Shi, C.; Fu, Q.; Wang, J.; Zhang, W.; Zhou, X. Process of oxidative conversion of methanol. 2013.

[45] Liu, H.; Iglesia, E. Oxidation of methanol and/or dimethyl ether using supported molybdenumcontaining heteropolyacid catalysts. 2005.

[46] Schelling, H.; Stroefer, E.; Pinkos, R.; Haunert, A.; Tebben, G. D.; Hasse, H.; Blagov, S. Method for producing polyoxymethylene dimethyl ethers. 2006. 
[47] Stroefer, E.; Schelling, H.; Hasse, H.; Blagov, S. Method for the production of polyoxymethylene dialkyl ethers from trioxan and dialkylethers. 2011.

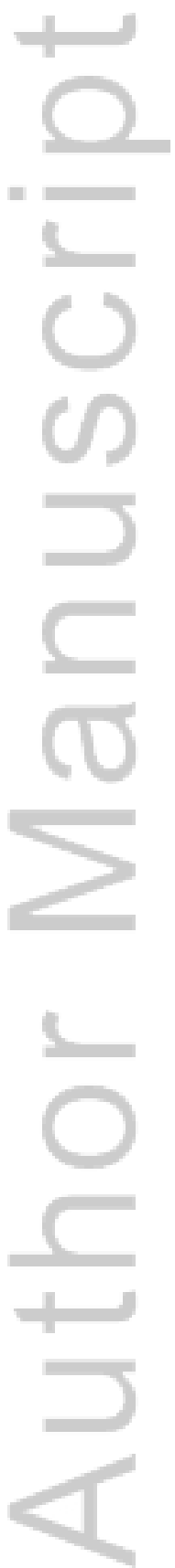

This article is protected by copyright. All rights reserved. 

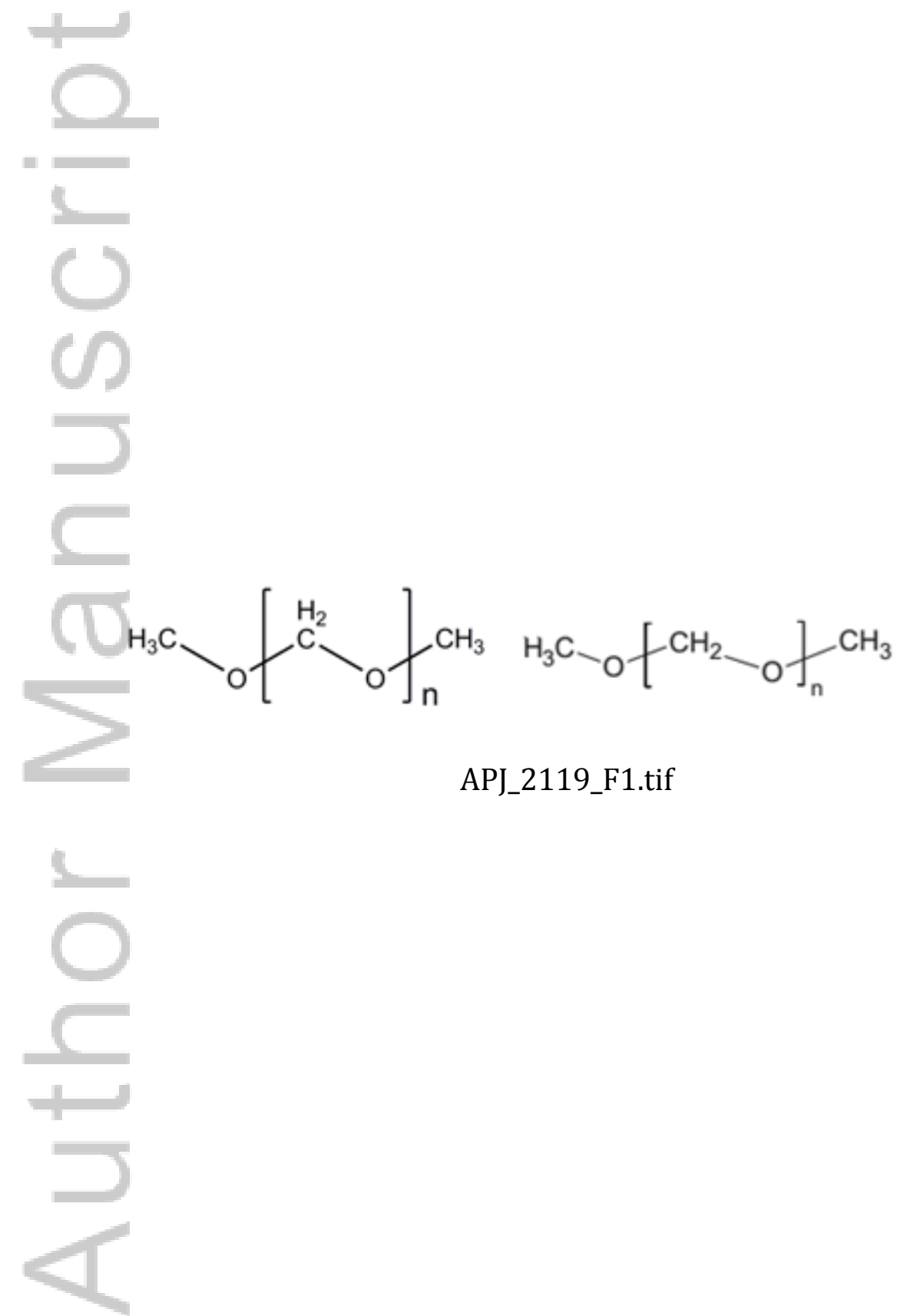

This article is protected by copyright. All rights reserved. 


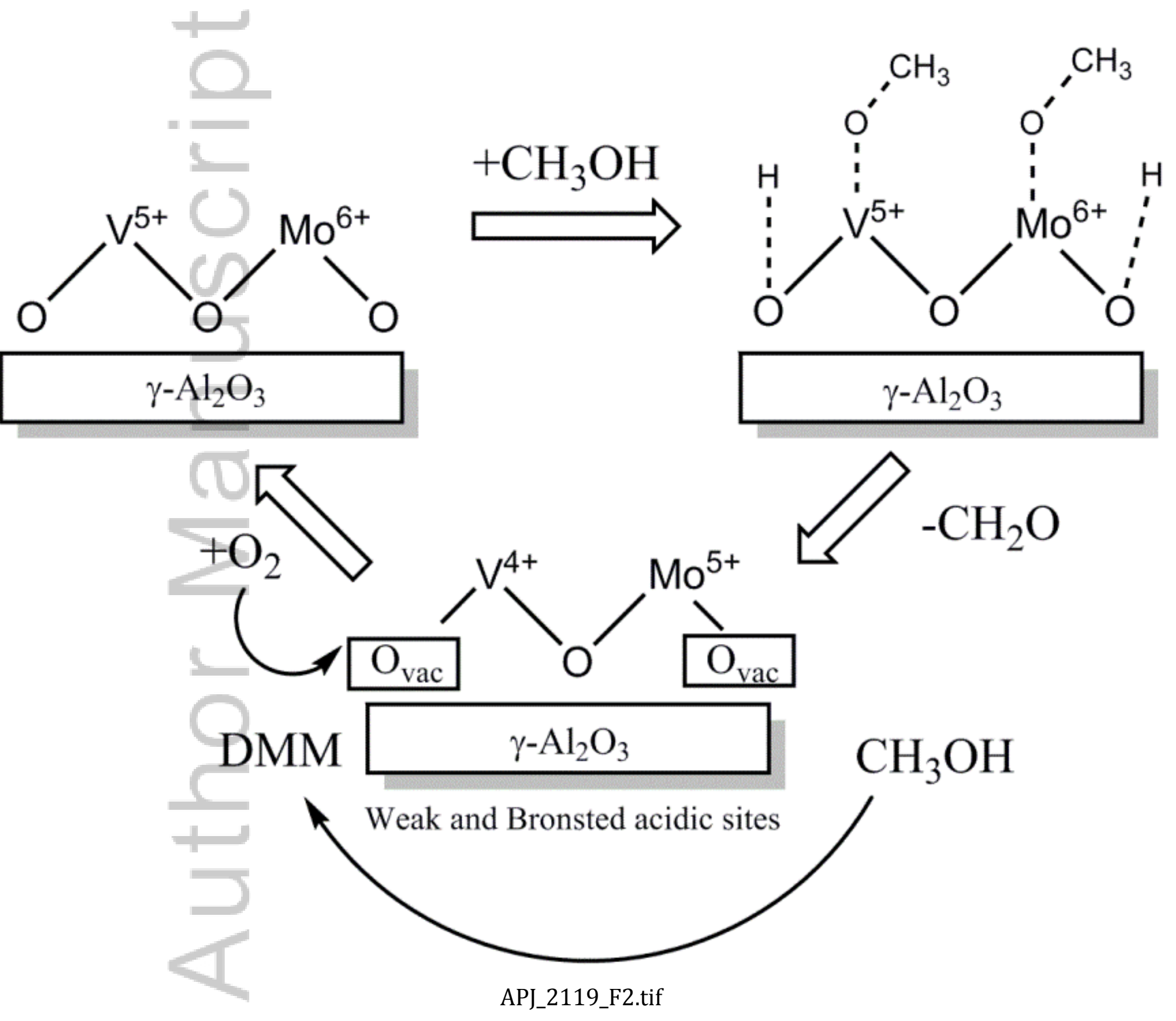




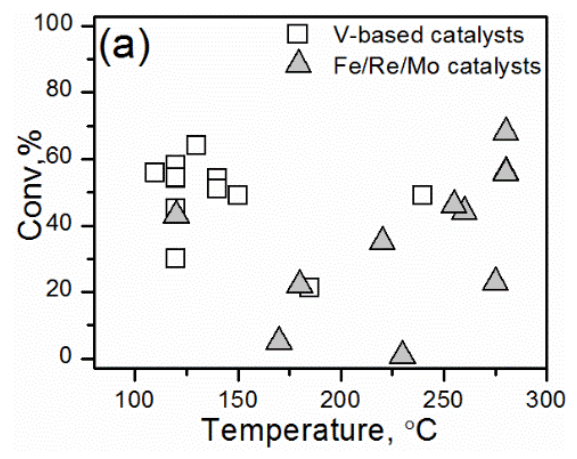

APJ_2119_F3-a.tif

This article is protected by copyright. All rights reserved. 


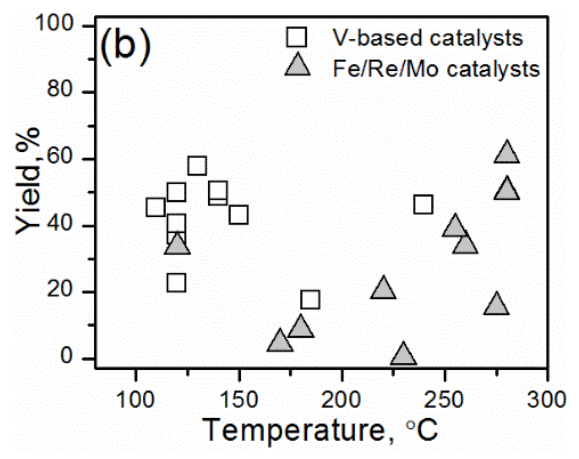

APJ_2119_F3-b.tif

This article is protected by copyright. All rights reserved. 


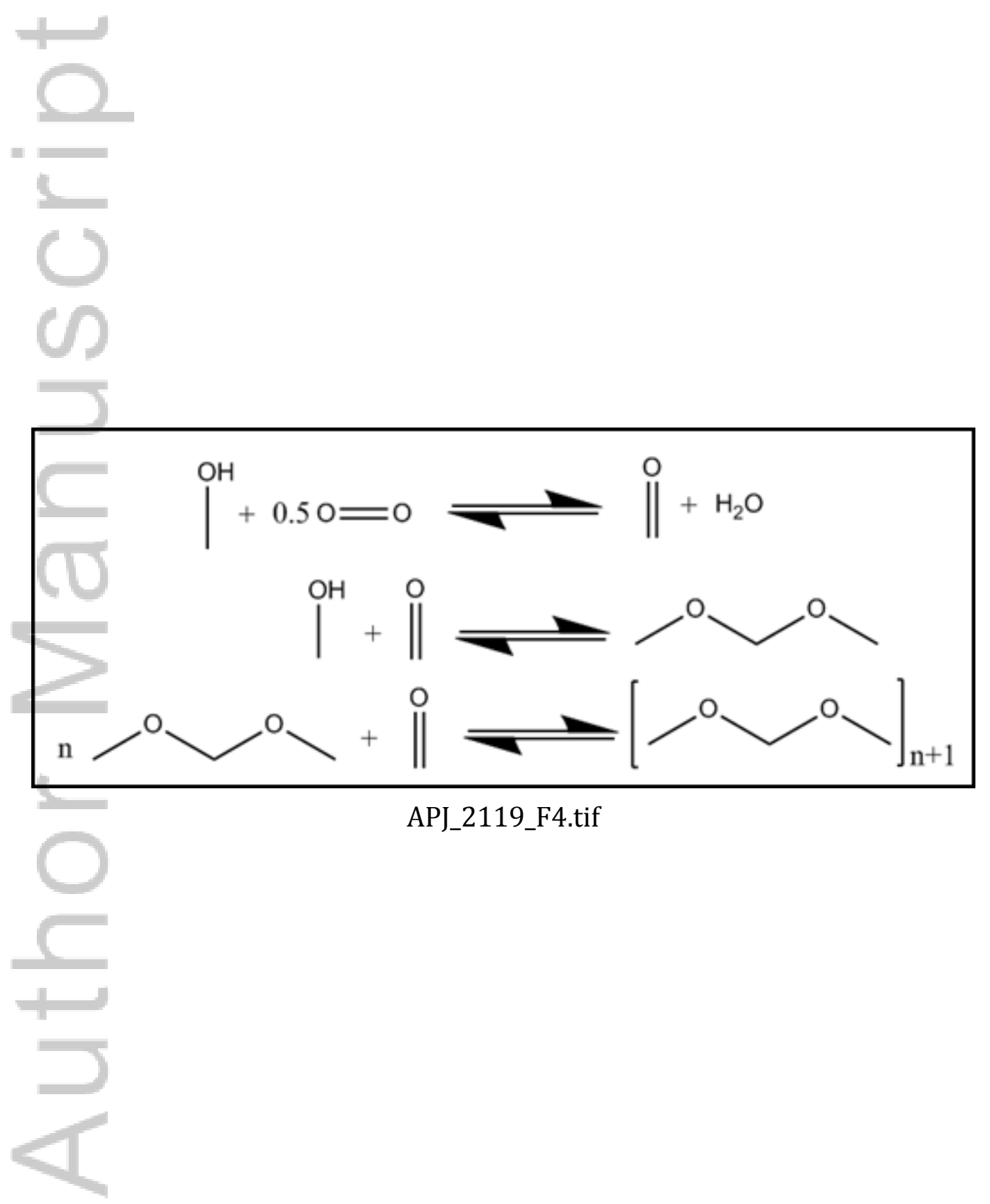

This article is protected by copyright. All rights reserved. 


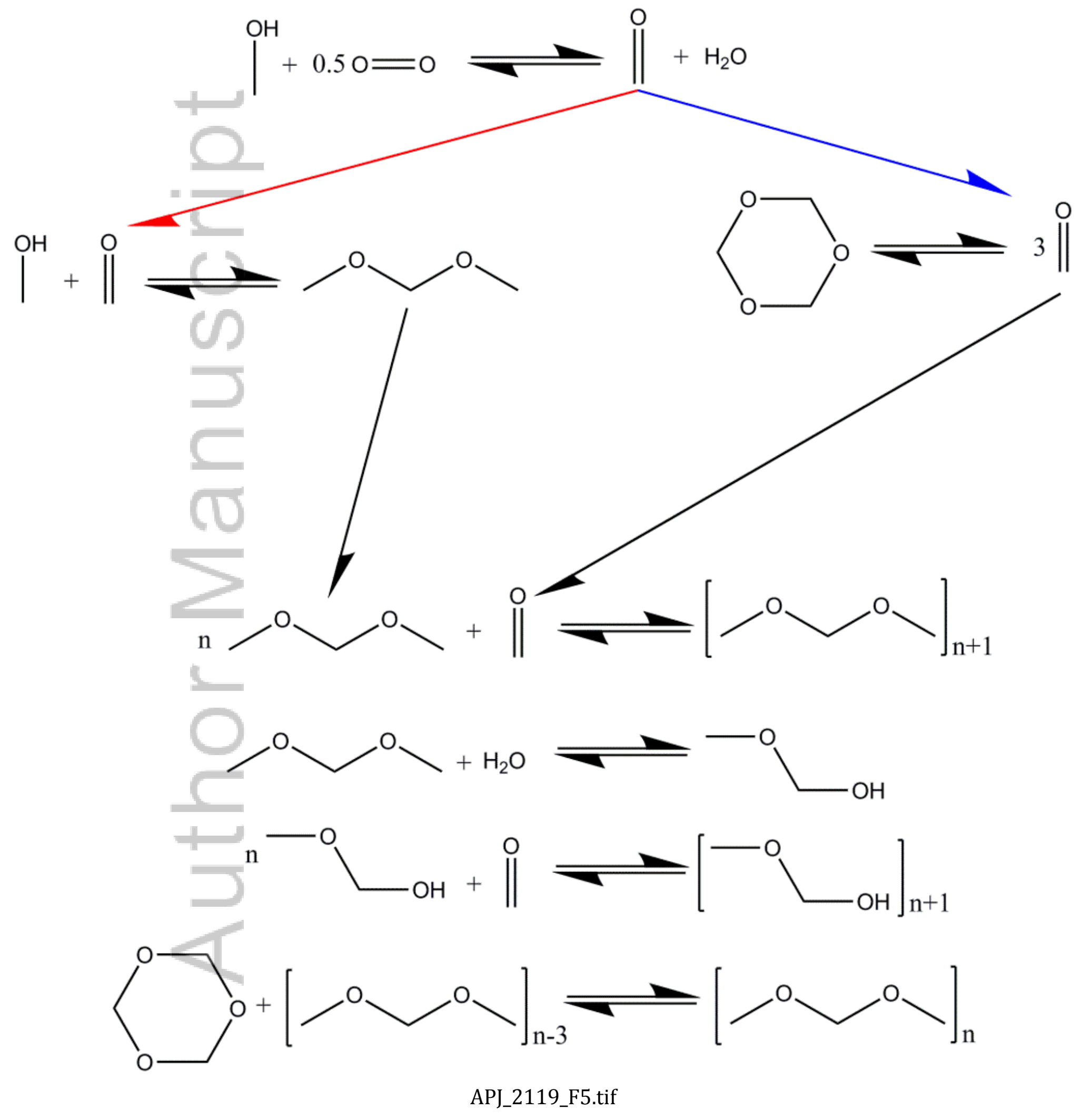

This article is protected by copyright. All rights reserved. 


\section{University Library}

\section{- M M N E R VA A gateway to Melbourne's research publications}

Minerva Access is the Institutional Repository of The University of Melbourne

Author/s:

Bhatelia, T;Lee, WJ;Samanta, C;Patel, J;Bordoloi, A

Title:

Processes for the production of oxymethylene ethers: promising synthetic diesel additives

Date:

2017-09-01

Citation:

Bhatelia, T., Lee, W. J., Samanta, C., Patel, J. \& Bordoloi, A. (2017). Processes for the production of oxymethylene ethers: promising synthetic diesel additives. ASIA-PACIFIC JOURNAL OF CHEMICAL ENGINEERING, 12 (5), pp.827-837. https://doi.org/10.1002/ apj.2119.

Persistent Link:

http://hdl.handle.net/11343/293273 